\title{
Allelopathic potential of some crop plant species on bread Wheat Triticum aestivum Using Equal compartment Agar Method.
}

\author{
Kawa Abdulkareem Ali \\ (Field Crops Dept., Agricultural College-Salahaddin University, Kurdistan Region-Iraq)
}

\begin{abstract}
This experiment was designed to study the allelopathic effect of durum wheat Triticum durum variety Symmit, Barley Hordeum vulgare variety Acsad 14 and Oat Avena sativa variety Narimski on bread wheat Triticum aestivum variety Aras in mixed culture using Equal Agar Compartment Method to exclude any competition effect. Results indicated the significant effect of root exudates of the three studies crop plants that affect the elongation and dry weight of Bread wheat variety Aras seedlings when compared to pure stand culture in such a way that durum wheat caused lowest radicle length while Oat crop root exudates minimized all recorded data. It was obvious that allelochemicals from studied crop seedlings root exudates caused the reduction in the recorded data of bread wheat seedlings under no-competition and no-nutrient environment that was created in the Equal Agar Compartment Method.
\end{abstract}

Keywords :-Allelopathy, Phytotoxicity, allelochemicals..

\section{INTRODUCTION}

Allelopathy was defined as any direct or indirect, beneficial or harmful effect of donor plant on a recipient plant through the release of chemical compounds known as allelochemicals that may have significant effect on both crop and weed plants (Kadioglu \& Yanar., 2004). While Competition was defined as the negative effect which one organism has upon another by consuming or controlling access to a resource that is limited in availability (Keddy.1989). Wheat crop is the main field crop in Iraqi Kurdistan region, the total average cultivated area was 469469 hectare for the years 2008-2011 that depends not only on the seasonally amount of precipitation but also on its distribution during growth season (Ismail, 2006) and (Marof 2007), therefore it is the most important crop in the region with the yield of $839 \mathrm{~kg}$. ha ${ }^{-1}$ (Khalaf., 2010). Weed plants, which defined as any strange or displaced plant, imposed the most important biological constraint that faces growth and yield of wheat crops, in no weed control fields it may cause about $45 \%$ yield losses (Al-Ali., 1980). Bread wheat (Triticum aestivum) varieties have been approved to have higher allelopathic activity when compared with companion plants in the field due to the production of allelochemicals which affect the growth of companion crops and weeds (Wu et al., 2002). Several crop plants also were investigated and reported as allelopathic plants such as Rice, Barley, Oat and durum wheat (Seal and Pratley.,2010), ( Wu et al., 1999) and (Belz and Hurul., 2004). If the crop plant seedlings have the allelopathic activity that helps it to control the growth of companion weed plants or any companion crop plants in mixed cropping ecosystem this will help the crop plants to benefit from all growth resources in order to build big vegetative parts which act as antenna for light catchment to gain more dry weight at early growth stages. Special experiments were designed to distinct between the two biological phenomenon (Allelopathy and Competition) to provide evidences about the reality of this incredible relation-ship, which mainly focuses on allelochemicals that defined as Chemicals released from plants and possess allelopathic effect (Olofsdotter and Malik, 2001). There is a newly developed method for studying allelopathic effects with completely excluding any competition effects that was introduced by (Wu et al., 2000) under the name of Equal-Compartment Agar method. Since the allelopathic studies were less focused on the allelopathic potential between crop plants, this study was conducted to evaluate the allelopathical potential of durum wheat Triticum durum variety Symmit, Barley Hordeum vulgare variety Acsad 14 and Oat Avena sativa variety Narimski toward bread wheat Triticum aestivum variety (Aras). The main objective of this study was to distinguish the competition effect from allelopathic relationship between studied crop plants and to evaluate the phytotoxic effect of of three crop plants which were; Barley, Oat and durum wheat on bread wheat seedlings growth.

\section{MATERIAL AND METHODS}

This study was conducted in laboratories of agricultural college, Salahaddin University. Wheat, Barley and Oat seeds were obtained from Arbil agricultural Research Center. Seeds were surface sterilized by socking in $2.5 \%$ sodium hypochlorite solution for 15 minutes then followed by five times rinsing in sterilized distilled water. The next step was preparing uniform seedlings by socking the surface sterilized seeds of bread and durum wheat, Barley and Oat each alone in sterilized water in petri-dishes at $25^{\circ} \mathrm{C}$ for 24 and 48 hours respectively with six replications for each crop seeds. Equal compartment agar method was persuaded by using 
glass beaker $(800 \mathrm{ml})$ containing $50 \mathrm{ml}$ semisolid $0.3 \%$ agar plus water that was previously autoclaved (Amini et al., 2010) and (Labbafy et al ., 2009). Twelve of pre-germinated seeds of bread wheat variety (Aras), durum wheat variety (Symmit), Barley and Oat were uniformly selected then transplanted on the agar surface with the embryo upward, on one half of the glass beaker, while for the other half of the beaker only twelve uniform pregerminated seeds of bread wheat variety (Aras) were transplanted on the agar surface with the embryo upward, thereby the beaker was divided to two equal compartments that contains (1) Bread wheat (Aras) plus Durum wheat Symmit (2) Bread wheat (Aras) plus Barley (3) Bread wheat (Aras) plus Oat (4) control which was Bread wheat (Aras) plus Bread wheat (Aras). Competition above the agar surface was excluded by separating each compartment using a peace of previously autoclaved white paperboard which was inserted across the center and down the middle of the beaker where the lower edge kept $1 \mathrm{~cm}$ above the agar surface. Root of tested seedlings where left to grow freely through the agar (no nutrient) in order to study root exudates that may affect the recipient plants. After that the beaker were raped with parafilm and kept in growth-chamber with $25 / 18^{\circ} \mathrm{C}$ day and night temperature respectively; 13/11 hours light/ dark period for 10 days (Wu et al., 2007). At the end of the experiment the recording data were radicle length $(\mathrm{cm})$, radicle elongation velocity $(\mathrm{cm} / \mathrm{day})$, plumule length $(\mathrm{cm})$, plumule elongation velocity $(\mathrm{cm} /$ day), radicle dry weight $(\mathrm{mg})$, plumule dry weight $(\mathrm{mg})$, and seedling total dry weight (mg), radicle and plumule growth inhibition rate the equations shown below (De-Oliveira et al., 2008) (Ali and Aziz, 2002) and (Norsworthy, 2003).

$$
\begin{aligned}
& \text { Radical or Plumule elongation Velocity }=\frac{\text { Radical or Plumule length }(\mathrm{cm})}{\text { Total number of days }} \\
& \text { Radical or Plumule growth inhibition }=\left(1-\left(\frac{\text { Value under stress }}{\text { value in nonstress conditions }}\right)\right) \times 100
\end{aligned}
$$

The statistical analysis for all data were performed using Statistical Package for the Social Sciences (SPSS version 18) and excel statistical programmer, while for mean comparisons duncan test was used (Weinberg and Abramowitz, 2008) and (Field, 2005).

\section{RESULTS AND Discussion}

Results of the recorded data in (table-1) indicated non-significant differences between plumule length of Bread wheat Triticum aestivum variety Aras when grown with other crop plants in ager compartments, while there was significant differences $(p<0.01)$ in radicle length of tested plant and the highest data was recorded in pure stands of Aras variety $12.90(\mathrm{~cm})$ when compared with mixed stands, meanwhile seedling total length was also significantly affected by mixed stand where the highest record was $28.11(\mathrm{~cm})$ in pure stand. Plumule dry weight wasn't affected significantly by the mixed culture of bread wheat Triticum aestivum Aras with the three other crop seedlings, but the radicle dry weight was significantly affected in mixed culture when compared with pure stand culture which was $7.26 \mathrm{mg}$ and in mixed culture were $4.23,4.36$ and $4.56 \mathrm{mg}$ in mixed culture with Oat, Barley and durum wheat, the same significant effect was obvious when data of seedling dry weight was recorded where the highest dry weight documented in pure culture of Aras variety comparing with mixed culture with tested crop seedlings. Inhibition percentage of plumule length of bread wheat Triticum aestivum Aras wasn't significantly affected by mixed culture in agar while in radicles inhibition percentage there were significant differences between pure culture and other mixed culture with other crop plants as shown in (figure1). Inhibition percentage in plumule, radicle and total seedlings dry weight when there was comparison between pure and mixed culture in agar indicated non-significant differences in inhibition of all plumule and seedlings total dry weight between pure and mixed culture, meanwhile percentage of inhibition in radicle dry weight showed significant differences between pure and mixed cultures of Bread wheat Triticum aestivum variety Aras (figure-2). Elongation velocity (cm/day) when compared for plumule of Bread wheat Triticum aestivum variety Aras in mixed and pure culture it did not documented any significant differences in both cases, but for radicle elongation velocity there were significant differences between both environment of Bread wheat Triticum aestivum variety Aras (figure-3). Results of this study indicate the high phytotoxic ability of Oat crop toward bread wheat crop plants as it caused the reduction of radicle and total seedlings dry weight comparing to control that reached 41.80 and $26.43 \%$ respectively which indicate the possibility of studying the oat crops different plant parts allelopathic potential toward different weed plants in the area through study the physiological and biochemical changes in recipient weed plants (Zuo et al. 2012). Taken together, these observations support the notion that allelopathic relationship do take place when root of seedlings where in vicinity with other crop plants (Alssadawi and Rice., 1982). Selection of high allelopathic potential crops which has the capability of suppressing companion weed plants through the exudation of phytotoxic compounds (Zuo et al., 2011) is an important issue for reducing the use of herbicides in controlling weed plants especially there are many evidences about the high ability of poacea family (Moreiras-sanchez et al., 2004) and (Macias et al., 2007). 


\section{CONCLUSION}

This study indicates that Oat Crop plants have high allelopathic potential toward Bread wheat Triticum aestivum variety Aras comparing to Durum wheat and Barley crops when we used Equal Agar Compartment Method in the study.

\section{Acknowledgements}

I would like to thank field crops department staff for their help during the implementation of this study and (Erbil research center-Kurdistan region-Iraq) and Dr. Sami Salih for providing certified crop seeds for this study.

\section{REFERENCES}

[1] Kadioglu, Izzet., Yusuf . Yanar. (2004). Allelopathic effect of plant extract against seed germination of some weeds. Asian. J. Plant Science.3 (4): 472-475.

[2] Keedy, A. Paul. (1989). Population and Community Biology -Competition. Chapman \& Hill . New york. USA.

[3] Ismail, B. K. (2006). Effect of water stress on growth, yield, and quality characteristics of eight bread wheat cultivars. MSc. Thesis. College of Science. University of Salahadin. Iraq.

[4] Marof, S. M. (2007). Competititive Interference Between Triticale x Triticosecale rimpaui Wittmac and Wheat Triticum spp . L. under two different environmental conditions. Ph D. Dissertation. College of Agriculture .University of Salahadin

[5] Khalaf, S. Ahmed. (2010). Principles of Field Crops. Dohuk University Publishing's. Dohuk.Iraq.

[6] Al-ali, Aziz. (1980). Guide of agricultural pest control. Agricultural ministry. Institute of plant protection.

[7] Wu,H., T.Haig., J.Prately., D.Lemerle., and M.An. (2002). Biochemical Basis for Wheat Seedling Allelopathy on the Suppression of annual ryegrass (Lolium rigidum) . Journal of Agricultural Food Chemistry .50: 4567-4571.

[8] Seal, An. J. E. Pratley. (2010). The Specificity of allelopathy in Rice ( Oryza sativa). Journal of European weed Research Society weed research .50: 303-311.

[9] Wu, H., J. Prately., D.Lemerle., and T. Haig. (1999). Crop cultivars with allelopathic capability. Weed Research. 39: 171-180.

[10] Belz, G. Regina., and Karl. Hurle. (2004). A Noval Laboratory Screening Bioassay for Crop seedling Allelopathy. Journal of Chemical Ecology. 30. (1): 175-198.

[11] Olofsdotter, Maria., and Azim,U, Malik. (2001). Allelopathy symposium. Agronomy Journal. 93(1): 1-2.

[12] Wu, H., J. Prately., D.Lemerle., and T. Haig. (2000). Laboratory Screening for Allelopathic Potential of wheat Triticum aestivum accessions against annual rye grass Lolium rigidum. Australian Journal of Agricultural Research 51, (2):259- 266.

[13] Amini, R., M. An., J. Partley and S. Azimi. (2010). Allelopathic potential of root exudates of annual ryegrass ( Lolium rigidum). Senenteenth Austrlasian weed Conference Proceedings. pp: 153-156.

[14] Labbafy, M. R., F. Maighany., A. Hejazy., H. Khalaj and A. M. Baghestany. ( 2009). Study of allelopathic interaction of wheat (Triticum aestivum L.) and rye (Secale cereal L.) Using equal-agar compartment method. Asian Journal of agricultural sciences. 1 (2): 25-28.

[15] Wu,H., Jim. Prately., Deirdre. Lemerle., Min.An., and Deli. Liu. (2007).Autotoxicity of Wheat (Triticum aestivum L.) as determined by Laboratory Bioassays. Plant Soil. 296: 85-93.

[16] De-oliveira, D. C., Geraldo. L. G and Isaias. R. D. (2008). Phytotoxicity of the extracts of Lonchocarpus muehlbergianus H. (Fabaceae) leaflets and galls on seed germination and early development of lettuce. Acta Botanica Brasilica. 22 (4): $1095-1100$.

[17] Ali, K. A. and F. H. Aziz. (2002). Studying the effect of root and shoot extracts of syrian cephalaria (Cephalaria syriaca) extract on wheat seeds (Triticum aestivum) germination properties. (Zanco) journal of pure and applied science. 14(2): 15-24.

[18] Norsworthy, K. Jason. (2003). Allelopathic potential of wild radish (Raphanus raphanistrum). Weed Technology. 17: $307-313$.

[19] Weinberg, S. L and Abramowitz, S. K. (2008). Statistics Using SPSS. Cambridge University Press.UK.

[20] Field, A. (2000). Discovering statistics using SPSS for windows Advance techniques for beginners. SAGE publications. London, UK.

[21] Zuo, S. p., Y. Q. Ma and L. T. Ye. (2012). In vitro assessment of allelopathic effects of wheat on potato. Allelopathy journal. 30 (1):1-10).

[22] Alsaadawi, I.S., and E. L. Rice. (1982). Allelopathic effects of Polygonum avicular .2. Isolation, characterization, and biological activities of phytotoxins. Journal of Chemical Ecology. 8(7): 1011-1023.

[23] Zuo, S. P., L.T. Ye and H. Mei. (2011). Physiological basis for allelopathic potential of different wheat cultivare in heading period on loess plateau of China. Affrican journal of Biotechnology. 10 (48): 9786- 9795.

[24] Moreiras-sanchez, A. M., O. A. Weiss and M. J. Reigosa- roger. (2004). Allelopathic evidences in the poaceae. The Botanical review. 69(3): 300-319.

[25] Macias, F. A., J. M. Molinillo., R. M. Varela and J. C. G. Galindo. (2007). Allelopathy - a natural alternative for weed control. Pest Management Science. 63 (4): 327- 348.

\section{Table 1: Effect of Spraying of wheat straw Aqueous extracts on some recorded data}

\begin{tabular}{|c|c|c|c|c|c|c|}
\hline treatment & $\begin{array}{c}\text { Plumule } \\
\text { length }(\mathrm{cm})\end{array}$ & $\begin{array}{c}\text { Radicle } \\
\text { length } \\
(\mathrm{cm})\end{array}$ & $\begin{array}{c}\text { Seedling } \\
\text { Length } \\
(\mathrm{cm})\end{array}$ & $\begin{array}{c}\text { Plumule } \\
\text { Dry } \\
\text { Weight } \\
(\mathrm{mg})\end{array}$ & $\begin{array}{c}\text { Radicle } \\
\text { Dry } \\
\text { Weight } \\
(\mathrm{mg})\end{array}$ & $\begin{array}{c}\text { Total Dry } \\
\text { Weight } \\
(\mathrm{mg})\end{array}$ \\
\hline Aras+Oat & $14.71 \mathrm{a}$ & $10.62 \mathrm{~b}$ & $25.33 \mathrm{~b}$ & $7.83 \mathrm{a}$ & $4.23 \mathrm{~b}$ & $12.06 \mathrm{~b}$ \\
\hline Aras+Barley & $15.49 \mathrm{a}$ & $10.53 \mathrm{~b}$ & $26.03 \mathrm{ab}$ & $8.86 \mathrm{a}$ & $4.36 \mathrm{~b}$ & $13.23 \mathrm{ab}$ \\
\hline Aras+Aras & $15.21 \mathrm{a}$ & $12.90 \mathrm{a}$ & $28.11 \mathrm{a}$ & $9.20 \mathrm{a}$ & $7.26 \mathrm{a}$ & $16.46 \mathrm{a}$ \\
\hline Aras+Durum & $15.16 \mathrm{a}$ & $10.45 \mathrm{~b}$ & $25.61 \mathrm{~b}$ & $7.96 \mathrm{a}$ & $4.56 \mathrm{~b}$ & $12.53 \mathrm{ab}$ \\
\hline
\end{tabular}




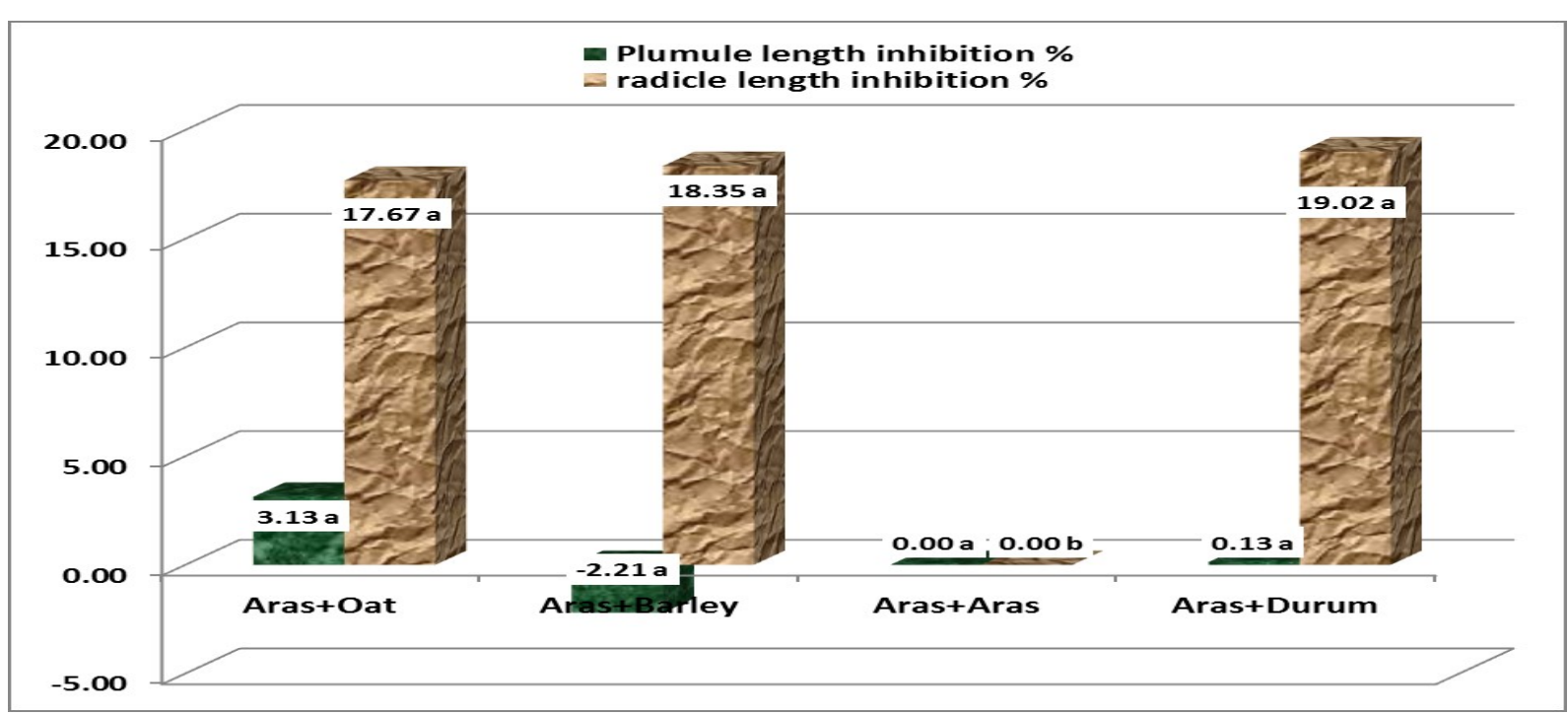

Figure 1: The effect of mixed culture on Length inhibition percentage of Bread Wheat Triticum aestivum Aras Variety

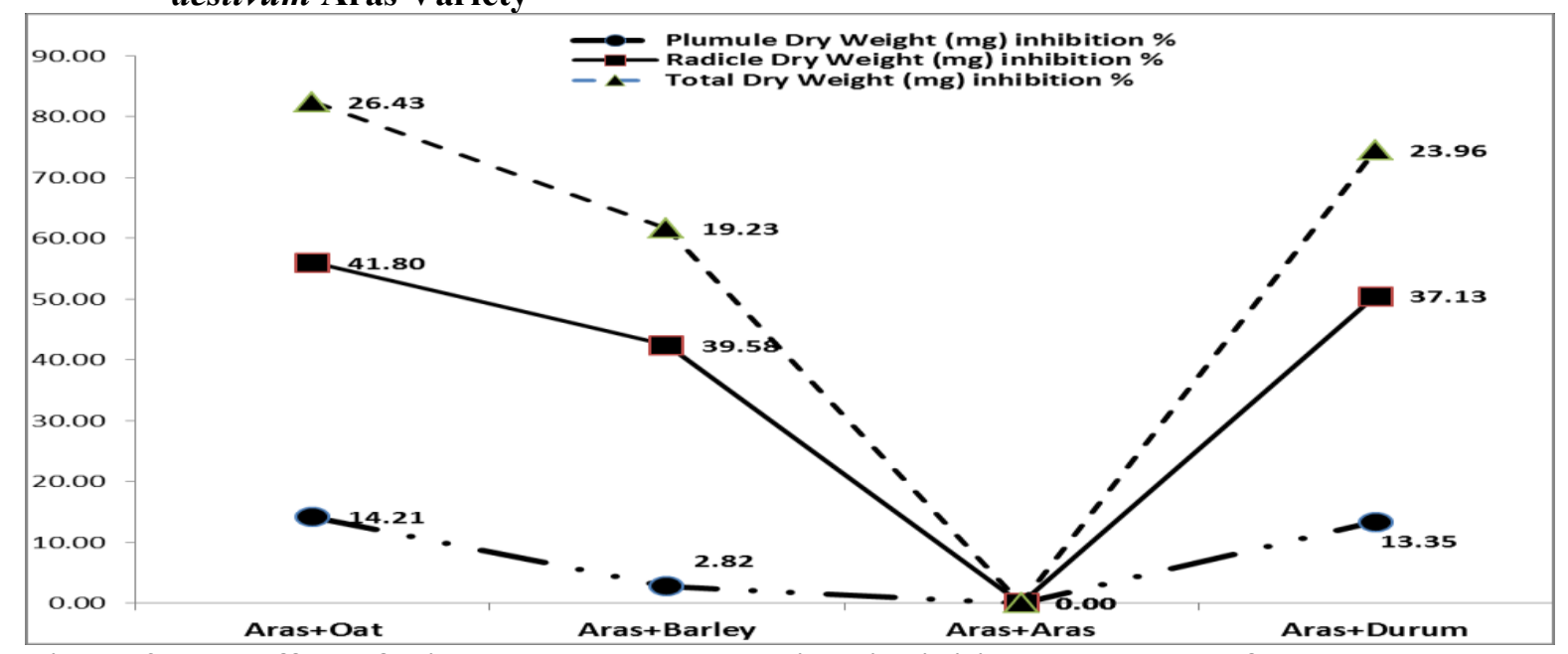

Figure 2: The effect of mixed culture on Dry weight inhibition percentage of Bread Wheat Triticum aestivum Aras Variety.

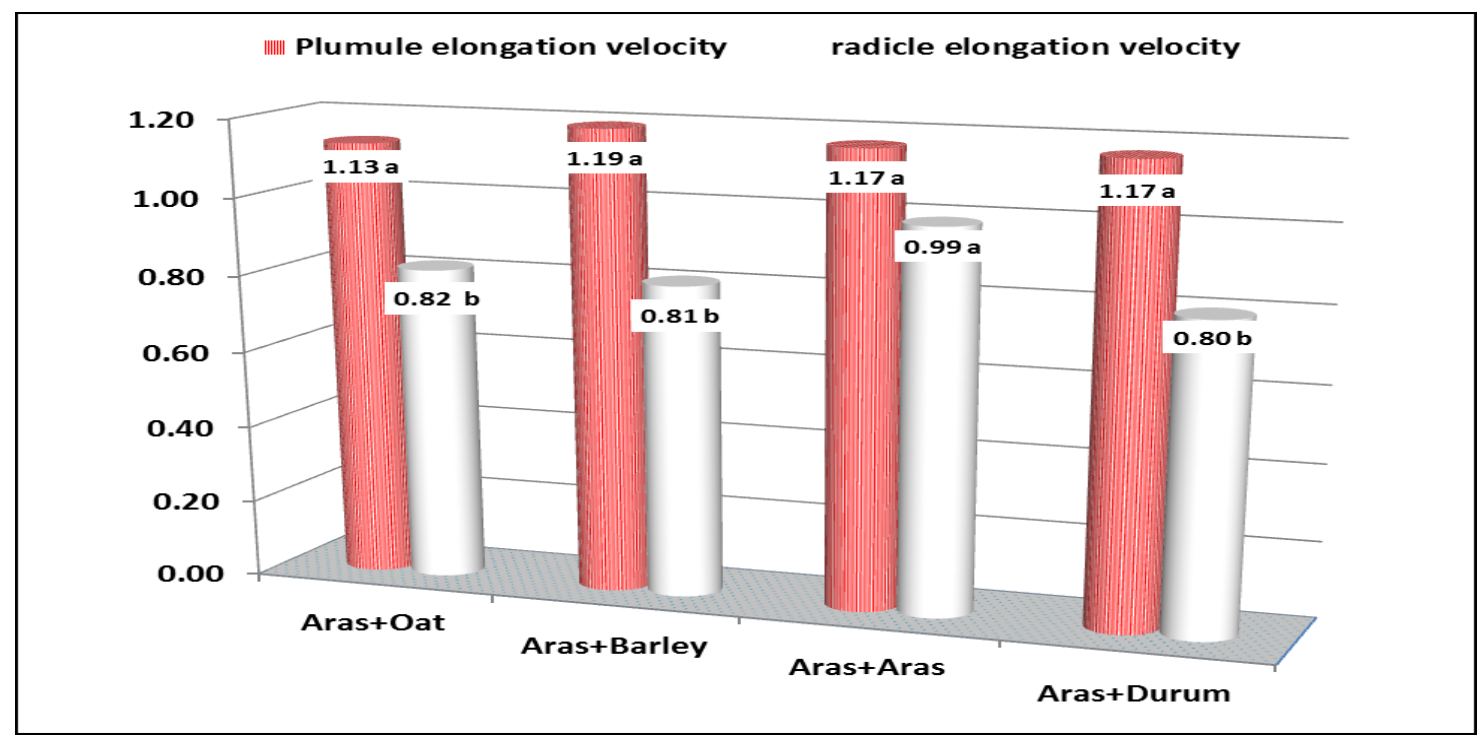

Figure 3: Effect of mixed culture on Plumule and Radicle elongation velocity of Bread Wheat Triticum aestivum Aras Variety. 